Cite as: Kolditz, O, McDermott, C \& Bilke, L 2012, 'OpenGeoSys: an open-source initiative for numerical simulation of thermo-hydro-mechanical/chemical (THM/C) processes in porous media' Environmental Earth Sciences.

\title{
OpenGeoSys: An open source initiative for numerical simulation of thermo-hydro-mechanical/chemical (THM/C) processes in porous media
}

\author{
O. Kolditz • S. Bauer, L. Bilke, N. Böttcher, J.O. Delfs, T. Fischer, \\ U.J. Görke, T. Kalbacher, G. Kosakowski, C.I. McDermott, C.H. Park, \\ F. Radu, K. Rink, H. Shao, H.B. Shao, F. Sun, Y.Y. Sun, A.K. Singh, \\ J. Taron, M. Walther, W. Wang, N. Watanabe, Y. Wu, M. Xie, B. Zehner
}

\begin{abstract}
In this paper we describe the OpenGeoSys (OGS) project, which is a scientific open source initiative for numerical simulation of thermo-hydro-mechanical-chemical (THMC) processes in porous media. The basic concept is to provide a flexible numerical framework (using primarily the Finite Element Method (FEM)) for solving multi-field problems in porous and fractured media for applications in geoscience and hydrology. To this purpose OGS is based on an object-oriented FEM concept including a broad spectrum of interfaces for pre- and post-processing. The OGS idea has been in development since the mid eighties. We provide a short historical note about the continuous process of concept and software development having evolved through Fortran, C, and $\mathrm{C}++$ implementations. The idea behind OGS is to provide an open platform to the community, outfitted with professional software engineering tools such as platform-independent compiling and automated benchmarking. A comprehensive benchmarking book has been prepared for publication. Benchmarking has been proven to be a valuable tool for cooperation between different developer teams, e.g. for code comparison and validation purposes (DEVOVALEX and CO2

BENCH projects). On one hand, object-orientation (OO) provides a suitable framework for distributed code development; however the parallelization of $\mathrm{OO}$ codes still lacks efficiency. High-performance-computin (HPC) efficiency of $\mathrm{OO}$ codes is subject to future research.
\end{abstract}

O. Kolditz $(\bowtie)$

Helmholtz Centre for Environmental Research - UFZ / TU Dresden

Permoserstrasse 15, D-04318 Leipzig, Germany

E-mail: olaf.kolditz@ufz.de
Keywords porous media $\cdot$ thermo-hydro-mechanical/ chemical · open source software · OpenGeoSys · carbon dioxide storage

\section{INTRODUCTION}

\subsection{Background}

Coupled process modeling has been considered in various engineering problems and geo-scientific applications since the computation method was introduced for problems of soil consolidation, dam construction and oil/gas field exploration in early 1970. However, substantial progress in experimental and theoretical studies regarding the fully coupled effects of temperature, hydraulics and mechanics, as well as chemistry, in fractured porous media was just made in the last two decades due mainly to demands from the performance and safety assessment of high-level nuclear waste repositories. Numerical methods and computer codes have been developed successfully within the international DECOVALEX project (www.decovalex.com). Meanwhile a wider range of applications associated with THMC coupled problems such as geothermal reservoir engineering, CO2 and energy storage, construction of underground repositories etc. can be found in different international conferences, e.g. GeoProc (www.mech.uwa.edu.au/research/geoproc), ComGeo (www.com-geo.org/).

For a long-term performance and safety assessment of a nuclear waste repository in a deep geological formation, an important issue is to guarantee the isolation of an underground repository. To answer this question, solute transport processes under the coupled conditions involving mechanical stability, ther- 
mal loading from the high-level waste, and chemistry in the groundwater should be predicted numerically. Also, for construction planning of such a complex and the implementation of experimental data gained from in situ tests, a multiple process coupled code is required.

Through the rapid development of computer technology, complicated geoscientific problems can be analyzed in a coupled manner using modern numerical codes. However, the understanding of the complicated coupled processes based on the experimental data available and implementation of the developed algorithm into the numerical codes are major challenge for scientists, which require interdisciplinary and interactive cooperation.

Quality management is nowadays a standard tool for production and development to ensure the high quality of a produced result. A numerical code dealing with the coupled THMC process is a highly complicated software product since the different processes have different characteristic features, e.g. time and spatial scales, nonlinearities, and interaction degree etc. To maintain a high quality of the developed code, benchmark testing is therefore necessary, especially in the case that scientists from different disciplines and organizations are working on the same code. Therefore, code verification and validation of selected test cases are documented during the code development, and finally a benchmarking book for the code development is produced and quality ensured (1).

\subsection{Historical note}

Considerable efforts have been made in the past for porous media code development to address above mentioned problems in geosciences and hydrology, e.g. TOUGH ((2), (3)), STOMP (4), HydroGeoSphere (5), FEFLOW (6), SUTRA (7) (8), DUMUX (9; 10), MIN3P (11), MT3D (12) or in particle hydrodynamics (13). In the abstract we describe the continuous development of OGS beginning in the eighties.

\section{RockFlow/FEFLOW-F:}

In the mid eighties there was a request by the Federal Institute of Geosciences (BGR) to the Institute of Hydromechanics (University of Hannover) concerning the development of a simulation program for fractured rock. The idea of RockFlow (RF) was then born and the development of a computer code based on multidimensional FEM in order to represent flow processes in complex geological structures. At the same time at the Academy of Sciences (Chemnitz) the FEFLOW code was being developed for density-dependent flow processes in porous media (14) (15). The pioneering work of RF-1 was done in a series of doctoral dissertations (16), (17), (18), (19). Both codes FEFLOW and RockFlow were implemented with FORTRAN at that time.

The next stage in the early nineties was related to the coupling of the individual RF-1 modules through file interfaces and the improvement of computational efficiency, e.g. by introducing an iterative equation solver. RF-2 was successfully used in several application projects in the fields of waste deposition and geothermal energy (20),(21). A scientific "market" for $\mathrm{RF}$ in Applied Geoscience was opened.

\section{RockFlow-C:}

It was soon determined that the coupling of the different RF modules via file interface was inefficient. Moreover, for the use of grid-adaptive methods, dynamic data structures were necessary. Consequently, in the late nineties a complete re-organization of $\mathrm{RF}$ was started. The implementation of RF-3 was started in $\mathrm{C}(22),(23)$. Major research topics of the RF group were multi-phase flow (24), grid adaptation (25), reactive transport (26), and deformation processes (27). Besides the numerical parts, geometric modeling and meshing methods became more and more important for real-world applications (28), (29).

\section{GeoSys/RockFlow-C++:}

Due to the increasing functionality, the RF code became more and more sophisticated and difficult to handle. Consequently, the introduction of object-oriented methods was necessary. RF-4 or now GeoSys was (again) completely re-designed and rewritten in $\mathrm{C}++(30)$, (31). Several doctoral theses have been completed in the fields of geotechnical simulation (DECOVALEX project, (32), (33), (34)), contaminant hydrology (Virtual Aquifer project, (35), (36), (37)), geothermal reservoir modelling (Urach Spa project, (38)). Alongside computational mechanics, progress had been made in the pre-processing for numerical analysis (39), (40), (41). First GeoSys/RockFlow habilitations had been completed (42), (43), (44). As mentioned in the beginning, it is impossible to cite everything. Other important works during the Tüebingen time are e.g. (45), (46), (47) concerning particle tracking, coupled hydrosystems, and reactive transport simulation. 


\section{Heat transport}

$$
\operatorname{c\rho } \frac{\partial T}{\partial t}=-\nabla\left(-K \nabla T+\sum_{\beta} h_{\beta} \vec{F}_{\beta}\right)+q
$$

\section{Thermodynamics}

Mechanics

\section{Deformation}

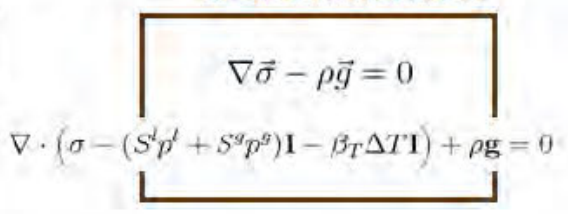

\section{Fluid flow}

$$
\begin{aligned}
& \frac{\partial}{\partial t} \int_{V_{n}} M^{\kappa} d V_{n}=\int_{\Gamma_{n}} \vec{F}^{\kappa} \vec{n} d \Gamma_{n}+\int_{V_{n}} q^{\kappa} d V_{n} \\
& M^{\kappa}=\Phi \sum_{\beta} \rho_{\beta} S_{\beta} X_{\beta}^{\kappa} \\
& \vec{F}_{\beta}^{\kappa}=-\rho_{\beta} \frac{\vec{k} k_{r \beta \beta}}{\mu_{\beta}}\left(\nabla P_{\beta}-\rho_{\beta} \vec{g}\right) \\
& \sum_{\beta} S_{\beta}=1
\end{aligned}
$$

\section{Chemistry}

\section{Reactive transport}

$$
\begin{gathered}
\overrightarrow{F^{\kappa}}=\sum_{\beta}\left(X_{\beta}^{\kappa} \overrightarrow{F_{\beta}}+\rho_{\beta} \overrightarrow{D_{\beta}^{\kappa}} \nabla X_{\beta}^{\kappa}\right) \\
\ln \left(K_{P, T}\right)=\frac{\Delta G_{P, T}^{0}}{R T} \\
K_{i}=\frac{a_{u,}^{u_{w, j}} \prod_{i}\left(\gamma_{i} C_{i}\right)^{\nu_{i, j}} \prod_{m}\left(a_{m}\right)^{\nu_{m, j}} \prod_{g}\left(f_{g}\right)^{\nu_{y, j}}}{\gamma_{j} C_{j}}
\end{gathered}
$$

Fig. 1: Mathematical framework for coupled THMC modeling

\section{OpenGeoSys:}

The new challenge for GeoSys is to continue its development as a distributed open-source project, i.e. sharing and widening the knowledge, as people from the GeoSys group receive offers and move to other places, and as the number of GeoSys partners increases. At the Helmholtz Centre for Environmental Research in Leipzig a new research platform TESSIN is available, which combines high-performance-computing (HPCLab and high-end visualization facilities (VISLab). Postprocessing becomes more and more important as more and more information becomes available, due to highresolution measurement techniques and HPC itself. A first medium-size HPC application has been realized in geotechnical modeling (48). The next $\mathrm{PhD}$ generation has grown up within the open-source framework showing the large variety of OGS applicability in hydrology (49), reactive transport in geotechnics (50), groundwater optimization (51), geothermal reservoir analysis (52), as well as high-resolution modelling of the water uptake in root systems (53).

Currently we are intensively working on improving the software-engineering for platform independence (CMake) and software quality, e.g. by automated com- piling and benchmarking with a continuous integration server (Jenkins). The graphical-user-interface (GUI) has become a valuable tool for visual data management and analysis (54). Visualization provides a scientific tool for insight into large and complex data sets (55). A considerable amount of time is spent to prepare OGS for student teaching and training courses, e.g. in the HIGRADE graduate school program. Code comparison as a means of cooperation has a long tradition in the OGS development, e.g. (56) (57) (58) (59). Meanwhile those works belong to the most cited OGS papers. Meanwhile OGS in profiting a lot from the community support, e.g. concerning the development of pre- and postprocessing tools by the Federal Institute for Geosciences and Natural Resources (BGR), GINA development, (60) and German Research Centre for Geosciences (GFZ) (61; 62).

\section{CONCEPTS}

Originally OGS was intended to be a flexible finite element simulator for solving multi-field problems. Therefore, the current version is strongly based on objectoriented concepts for numerical purposes (sec. 2.1). At the same time, dealing with complex, real world 
problems requires the development of interfaces for advanced pre- and post-processing purposes, e.g. for geometrical modeling, meshing and visualization (sec. 2.2 ).

\subsection{Object-Oriented (OO) FEM}

Fig. 1 shows the mathematical framework to be solved when dealing with THMC processes in porous media.

- T process: Heat transport in multiphase systems including phase changes (e.g. evaporation, condensation, latent heat),

- H process: Non-isothermal multiphase flow of liquids and gases as well as supercritical fluids,

- M process: Non-isothermal elastic and in-elastic deformations,

- C Process: Multi-componental mass transport as well as bio/geochemical reactions.

The resulting balance equations for mass, momentum and energy conservation have to be completed by corresponding equations of state (EoS) and constitutive laws (e.g. plasticity and creep of clay and salt rock, respectively). The tetrahedron in Fig. 1 illustrates the strong degree of coupling between the different processes which requires adequate numerical methods for coupling partial differential equations.

The general idea behind object-orientation of processes is that the basic steps of the solution procedure: calculation of element contributions, assembly of equation system (including treatment of boundary conditions and source terms), solution of the equation systems, linearization methods and calculation of secondary variables, are independent of the specific problem (e.g. flow, transport, deformation processes). The process (PCS) class provides basic methods in order to solve a PDE in a very general way. Fig. 2 depicts the concept of object-orientation for the finite element method (OO FEM) implemented in OGS (63). The PCS object is designed to manage the complete solution algorithm in order to build the global equation system (EQS). In fact, the PCS object 'only' administrates references to geometric (GEO) objects (points, polylines, surfaces, volumes); $\mathrm{MSH}$ objects (mesh nodes, elements and mesh topology), node-related data such as initial (IC) and boundary (BC) conditions as well as source terms (ST); material data of porous media (fluid (MFP), solid (MSP), medium (MMP) and chemical (MCP) properties); parameters of the different numerical methods (NUM).

\subsection{Pre- and Post}

Professional pre- and post-processing methods and tools have become more and more important for numerical analysis as the complexity of models, as well as the availability of high-resolution data, has increased significantly. OGS is trying to address these challenges in different ways.

- Development of an OGS data explorer for visual data processing (Fig. 3),

- Providing interfaces to a large variety of specialized software and common interfaces (Fig. 4),

- Utilizing scientific visualization for model development, computational steering and outreaching research results (Fig. 12),

- Using platform independent software-engineering technologies for distributed code development and maintenance,

- Fostering open source activities - which is a basic philosophy behind the OGS project.

The user Interface of OGS Data Explorer (OGS$\mathrm{DE}$ ) is depicting the integration of a typical data set for hydrological modeling in Fig. 3. A raster file and the boundary of the model region have been imported into the software along with boreholes and precipitation data. Also shown are detailed views of a time series curve and a borehole stratigraphy from the investigation site in the Middle East. In addition to typical GIS tools, based on data integration OGS-DE can generate models or numerical analysis (e.g. groundwater models) and represent the computational results in the geographical / geological context. Graphical methods are based on VTK and are suitable for 3D visualization.

Fig. 4 shows the implemented interfaces for datainput (top row), data-output (bottom row) and native OGS files. Native files are currently in the process of being converted to XML to ensure easy validation of files and conversion to other file formats. OGS supports many standard file formats such as GeoTiff andimage formats for raster data, as well as ESRI shape files for vector data. In addition, a number of hydrological and geological software formats can be imported (e.g. GMS, Petrel, GOCAD) as well as the scientific open source data format netCDF which might be very useful for code comparison purposes and for 3D data visualization. The native file formats of our software are largely compliant with XML specification. While taking into account existing standards such as the GML-standard by the Open Geospatial Consortium or Google's KML, the file format used by OGS is much more compact for geographical information. It also includes additional information needed 


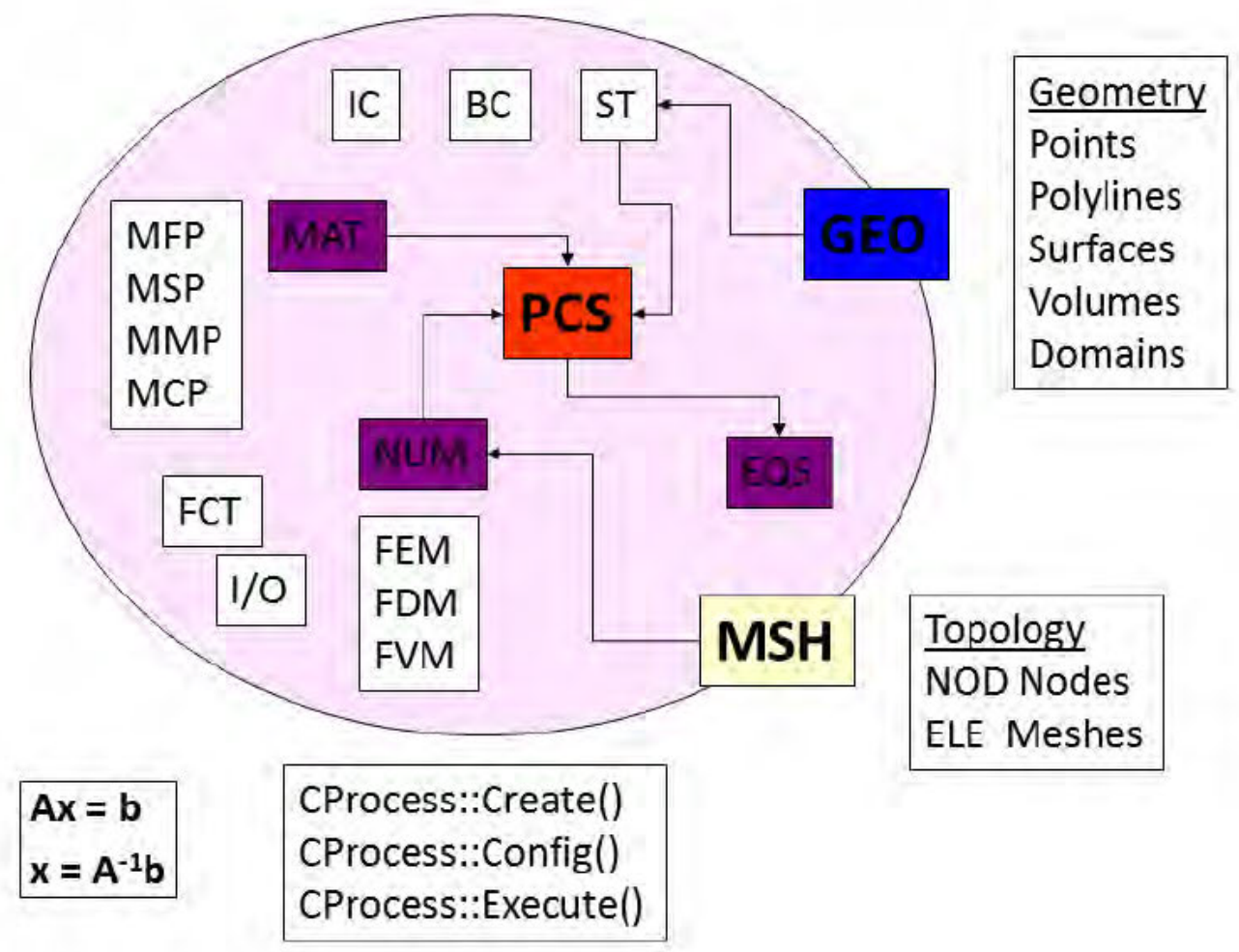

Fig. 2: Object-oriented concept for numerical solution of THMC coupled problems

for simulation processes which is not covered in the standards mentioned above. This way, we keep all the advantages of the XML specification such as the easy validation of files, extensibility and mapping to other standards via XSLT, etc., while using a file format specific to our needs. Furthermore, OGS employs a database interface that supports all established systems.

\section{APPLICATIONS}

We briefly introduce the potential of THM/C modeling in geotechnics and hydrology, as well as energy extraction and energy storage.

\subsection{Geotechnics}

Physical coupling phenomena of thermal (T), hydraulic $(\mathrm{H})$, and mechanical (M) processes are fundamental for the analysis of deep geosystems under high temperature, pressure and stress conditions. Sound understanding and predictability of THM processes including chemical reactions (C process) are important to a large variety of geotechnical applications such as nuclear and chemo-toxic waste disposal, geothermal energy, carbon capture and storage as well as gas and oil production. These geoscientific applications all share the same physio-chemical basics which emphasizes the importance of reliable THM/C codes. Specific examples include:

- the geological environment and different rock types, i.e. crystalline rocks, volcanic rocks, sandstones, clay, bentonite, ...

- the geofluids, i.e. water, brines, vapour, methane, carbon dioxide, gas hydrates ...

- the thermodynamic conditions, i.e. temperature, stress, pressure, salinity, ...

Fig. 5 illustrates the application area - nuclear waste disposal. Several concepts exist concerning host rocks for the disposal of hazardous waste in deep geological media, i.e. crystalline, salt, sediment, and volcanic formations. Different buffer systems are under discussion as geotechnical barriers for waste isolation i.e. crushed salt, bentonite, and bentonite/sand mixture. THM/C coupled modeling is required for the long-term risk assessment of possible processes which might result in a release of contaminants from the repository (64). The crucial question is how long it 


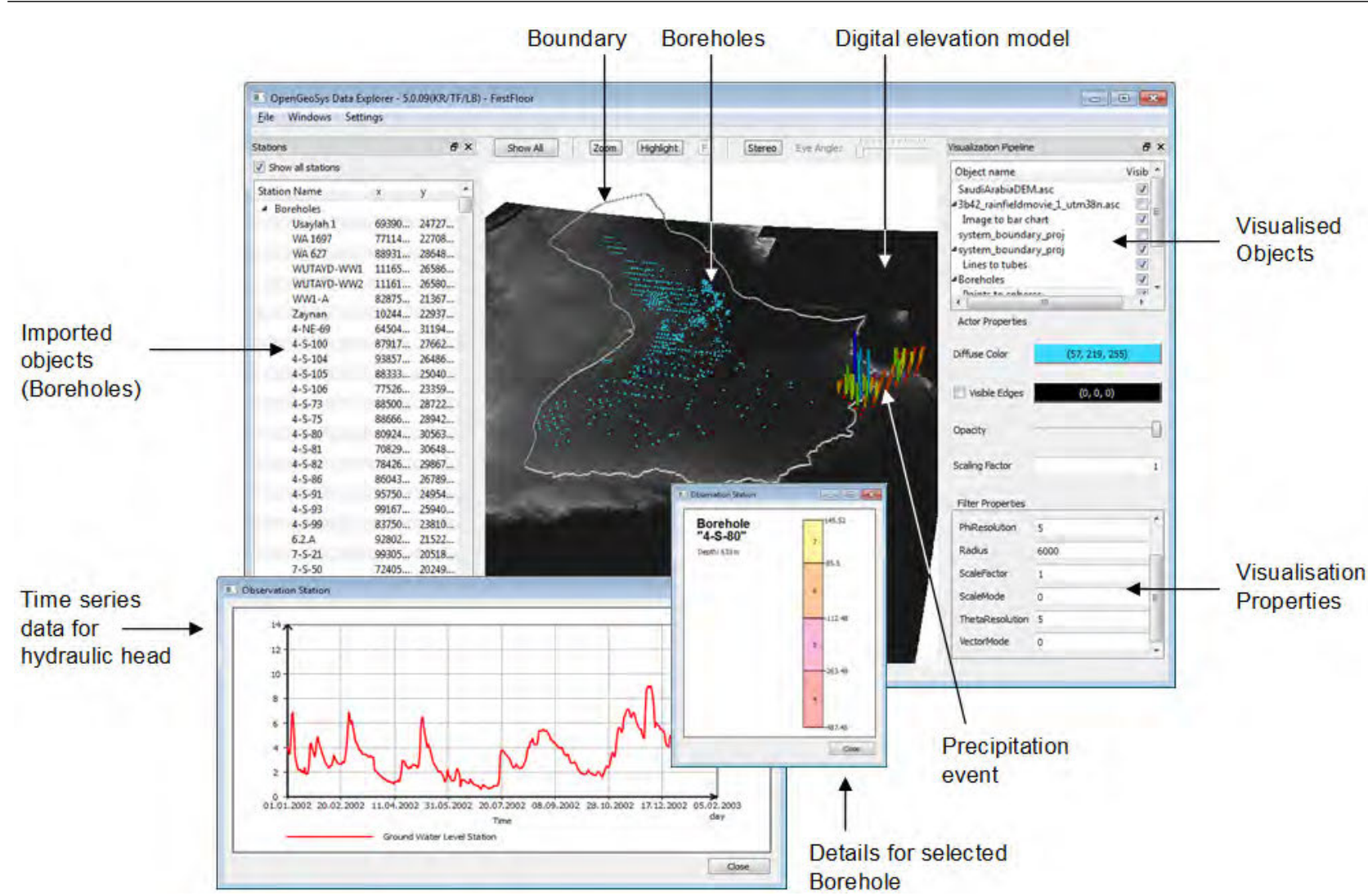

Fig. 3: Outline of the OGS graphical user interface for data exploration and integration (OGS-DE)

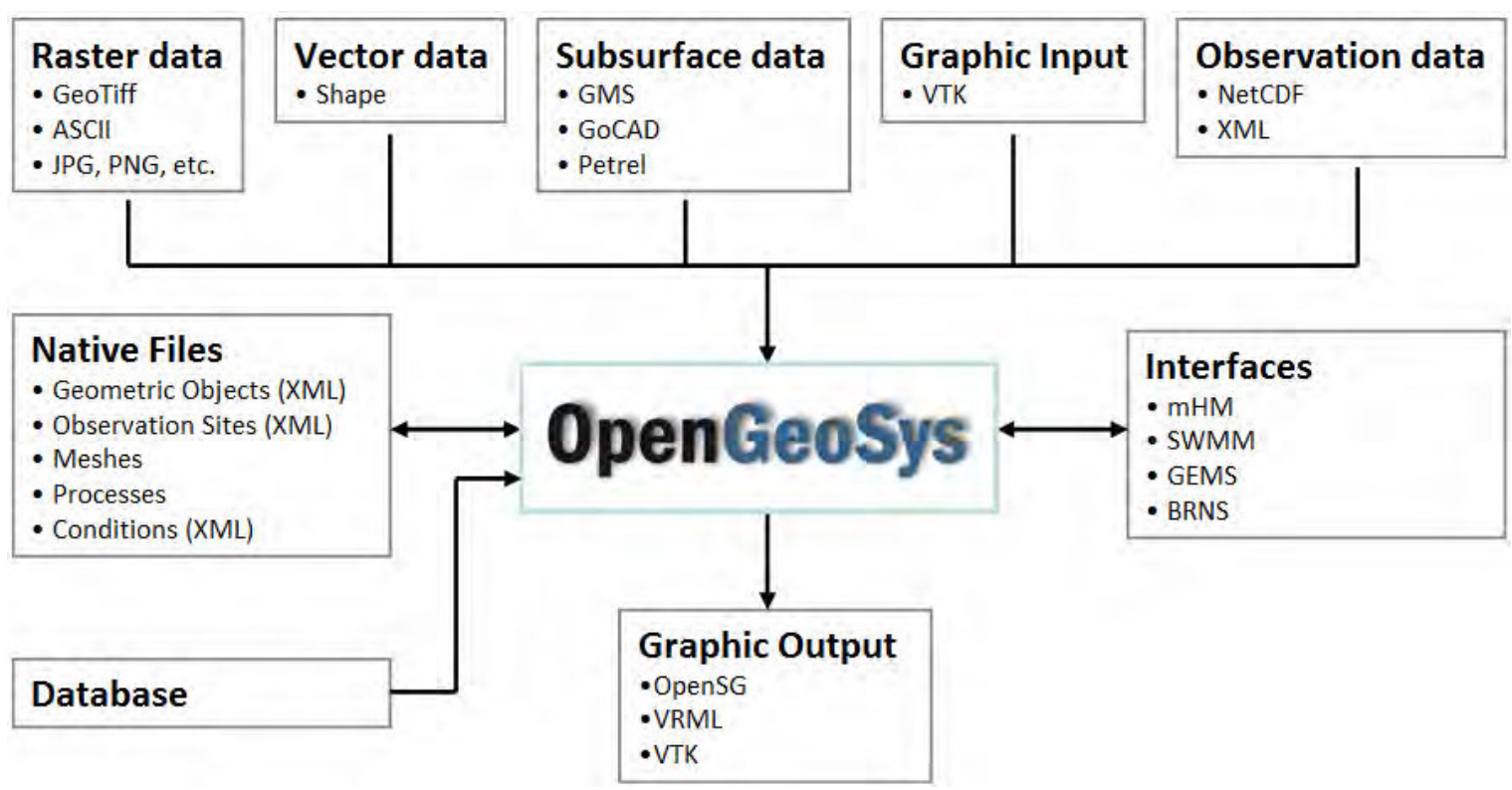

Fig. 4: Overview of OGS interfaces for data import and 3D visualization 


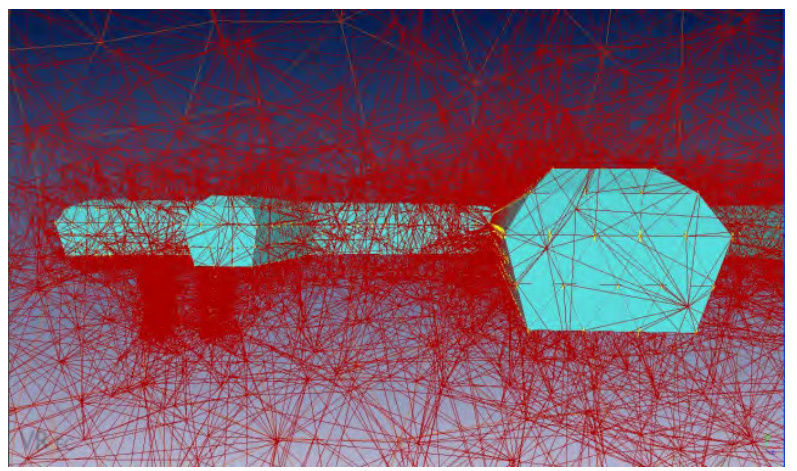

Fig. 5: THM modeling in a tunnel system (Visualization by B. Zehner)

would take - in the worst case - until contaminants could appear in the biosphere. Modeling is an important tool for risk assessment.

Fig. 6 depicts the application area - carbon capture and storage (CCS). The question is how to safely deposit $\mathrm{CO}_{2}$ from power plants by liquefying and injecting it into the subsurface for long-term storage. Two basic concepts for geological storage are under discussion: depleted gas reservoirs and deep saline aquifers. After many years of operation numerous former gas reservoirs are depleted. These reservoirs are in an underpressurized status and can take up large volumes of fluids. Keeping the reservoir under-pressurized, impervious cap rocks and borehole sealing are important considerations for storage. THM/C modeling is required in order to calculate possible fluid storage capacity, to assess risks and to better understand the highly coupled processes in the $\mathrm{CO}_{2}$ injection area as well as their consequences for optimal storage concepts (65).

Fig. 7 shows the application area geothermal energy, which is one of the alternative future energy resources under consideration. So-called shallow and deep geothermal systems can be exploited. Shallow systems are already commercially used, e.g. for heating purposes. Deep geothermal reservoirs can be used for electric power production as high temperatures up to $200 \check{\mathrm{r}} \mathrm{C}$ can be produced. THM/C modeling is required to design these geothermal power plants, e.g. in order to optimize production efficiency and reservoir lifetime. The significant cooling of the reservoir due to fluid reinjection gives rise to thermo-mechanical effects which need to be controlled in order to avoid reservoir damage (52).

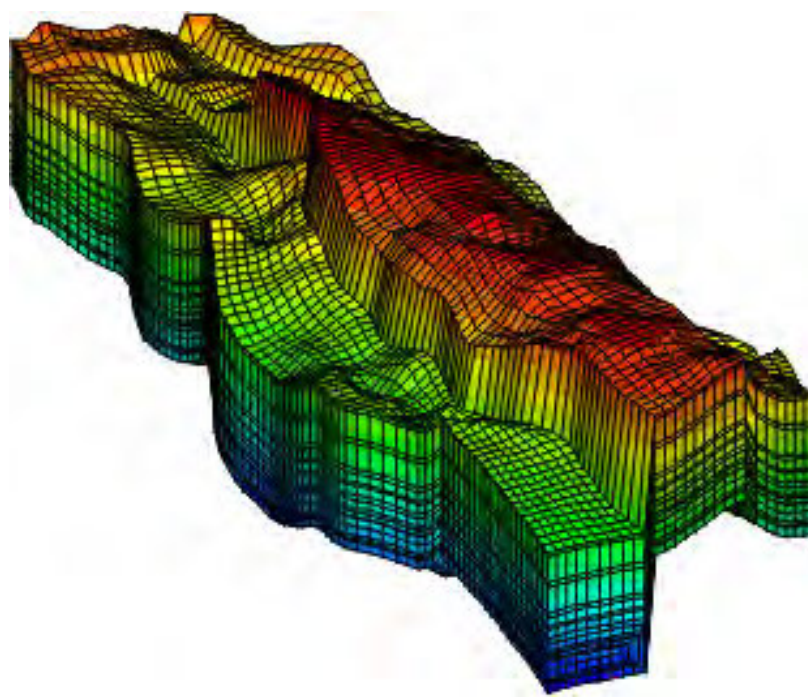

Fig. 6: Subsurface reservoir for CO2 storage

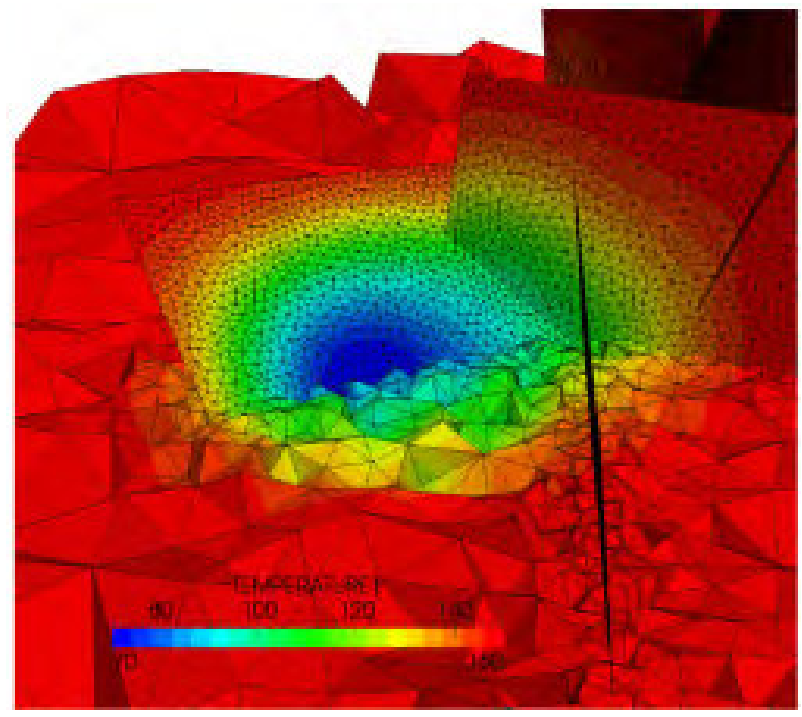

Fig. 7: Simulated temperature field of water reinjection into a geothermal reservoir

\subsection{Hydrology}

The second application area for coupled process simulation is hydrology (66). River basins or catchments are also subject to THM/C coupled processes, but include however a completely different range of thermodynamic conditions than deep geological systems. Hydrological processes are very complex to describe as they vary highly in time and space. The evaluation of groundwater recharge is vital to a sustainable water resources management (so called safe yield). To this purpose, i.e. the understanding of small scale phenomena such as root / soil water interaction is of tremendous significance (53). Typically groundwater mod- 
els are used for management purposes, particularly in semi-arid areas such as the Jordan Valley in the Middle East (67).

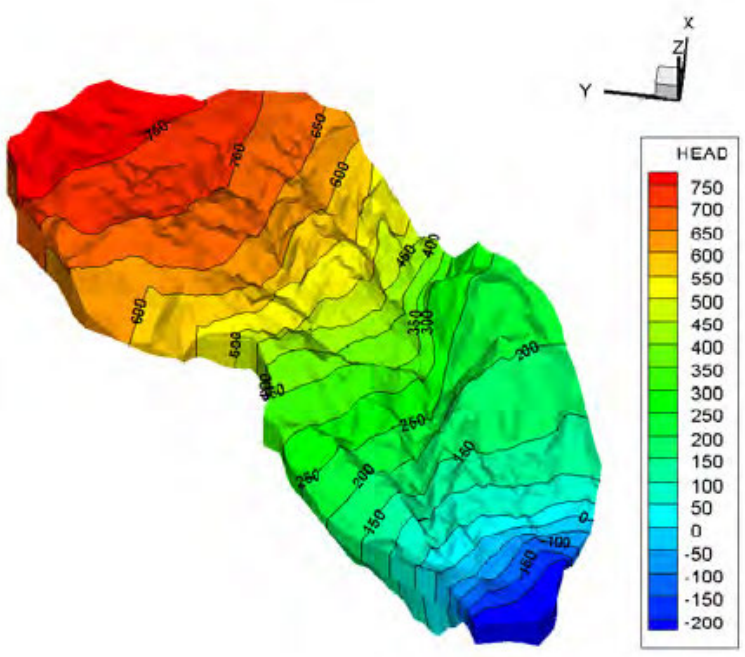

Fig. 8: Groundwater model for the Wadi Kafrein catchment in Jordan

Because water availability is an important issue in semi-arid and arid regions, groundwater quality deterioration is a critical concern in many urban areas of the world. Fig. 9 shows as an example part of a groundwater quality model prepared for the Nankou basin in the greater Beijing area. The idea of this modeling project is to identify possible sources of nitrate contamination originating from intense agriculture and fertilizer production (68). Land use and climate changes will impact the availability and quality of water resources to a large degree in the future. The modeling should help to develop scenarios for improving the groundwater quality in the long term. Areas subject to large groundwater extraction are also subject to severe land subsidence.

\subsection{Energy storage}

A very recent research area for THM/C modeling has become energy storage. The economy and feasibility of renewable energy sources will depend a large degree on efficient energy storage systems. Fig. 10 shows the numerical simulation of flow and heat distribution in a solid thermal energy storage block, which will be used to store solar energy collected during the daytime for use at night (so called solar-thermics). The long term

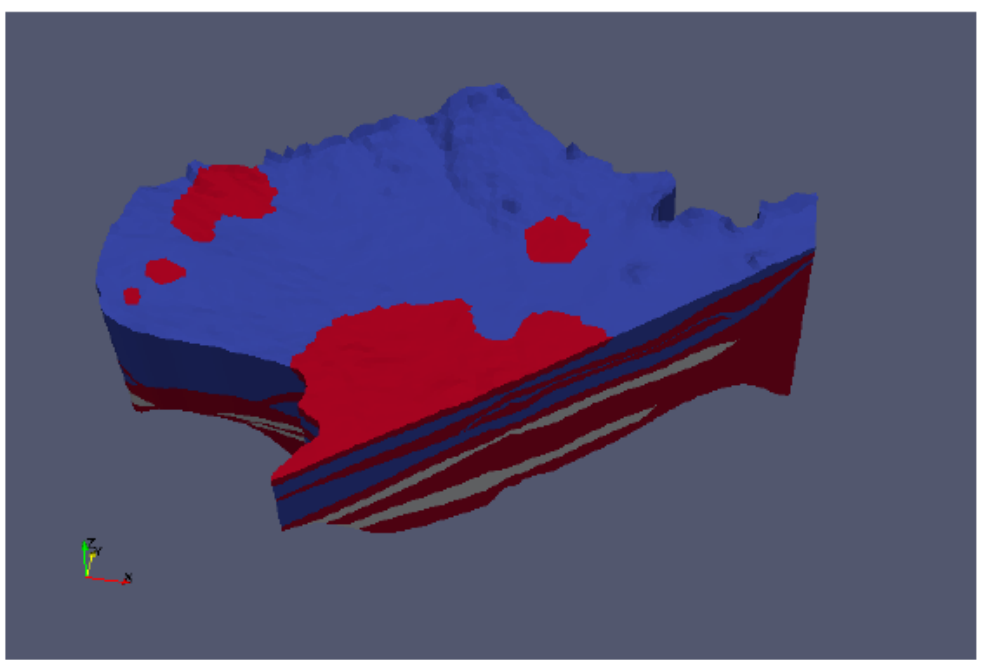

Fig. 9: Nankou groundwater quality model (68)

stability and efficiency of those energy storage devices can be optimized using THM/C modeling (i.e. solving the inverse geothermal problem). In addition to thermal storage, thermo-chemical concepts are under development, i.e. storing thermal energy by triggering endothermic reactions and gaining thermal energy back on demand with the reverse reaction (exother$\mathrm{mic})$.

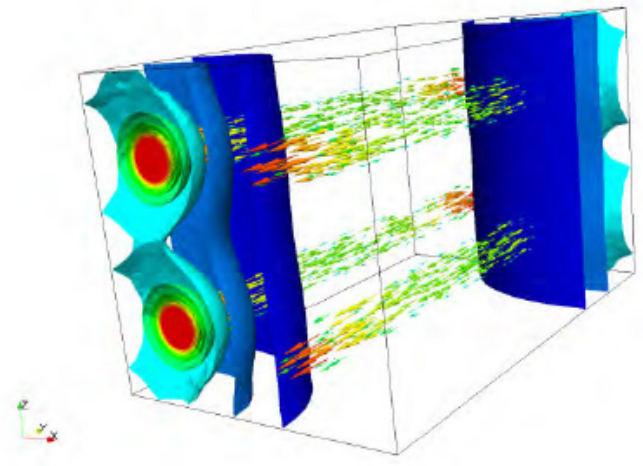

Fig. 10: Optimizing energy storage concepts by modeling (OGS simulation by Wenqing Wang)

\section{OUTLOOK}

We presented OGS as a scientific open source project which offers a platform for joint research activities in a large variety of geoscientific and hydrological disciplines. The success of the OGS idea will depend mainly on the community effort with regards to: 
- Continuous contributions to the repository,

- Software-engineering concept, coding conventions,

- Participating in code debugging, providing new benchmarks for code testing,

- Organizing of training courses, teaching activities,

- Joint research activities, joint publications (scientific impact is most important),

- ... unexpected ideas to make the OGS initiative more attractive.

Benchmarking has been recognized as an efficient tool for scientific collaboration. Recently, PNNL, LBNL, UFZ and others have begun establishing workshop series to foster the benchmarking idea: setting up test cases with increasing complexity for method development and code comparison (Fig. 11). In addition to representing model complexity, one of the key efforts is to develop codes which are suitable for modern HPC platforms such as PetaFlop supercomputers. It has been realized that those challenges are beyond single team capabilities. Some of these on-going initiatives are e.g. HydroBench (for hydrological concepts), $\mathrm{CO} 2 \mathrm{BENCH}$ and CO2FRAME (for $\mathrm{CO}_{2}$ storage).

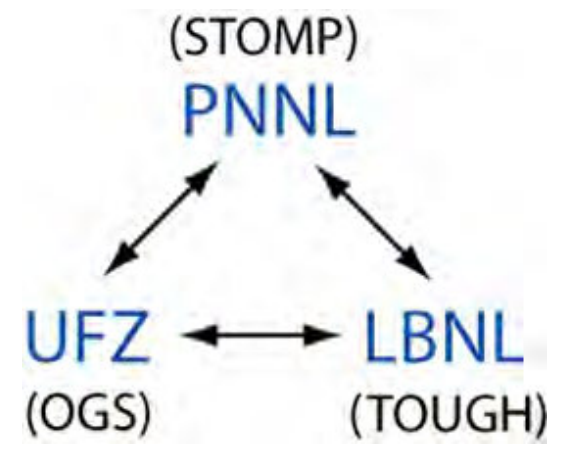

Fig. 11: International benchmarking initiative

\section{Acknowledgements}

We acknowledge the support of the OpenGeoSys project by following institutions:

- Academy of Sciences (former GDR)

- BGR Hannover

- University of Hannover

- Deutsche Forschungsgemeinschaft (DFG)

- Federal Ministry of Education and Science (BMBF)

- University of Tübingen

- Helmholtz Center for Environmental Research (UFZ)

- Technische Universität Dresden

The authors are very grateful to Alissa Hafele for language editing this paper.

\section{References}

1. Kolditz O, Goerke U, Shao H, Wang W, (eds). Benchmarks and examples for THMC processes in porous media. 1st edn., Springer: Berlin, 2011,forthcoming.

2. Pruess K. The TOUGH codes - A family of simulation tools for multiphase flow and transport processes in permeable media. Vadose Zone Journal 2004; 3(3):738-746.

3. $\mathrm{Xu} \mathrm{T}$, Sonnenthal E, Spycher N, Pruess K. TOUGHREACT - A simulation program for nonisothermal multiphase reactive geochemical transport in variably saturated geologic media: Applications to geothermal injectivity and $\mathrm{CO} 2$ geological sequestration. Computers $\&$ Geosciences 2006; 32(2):145-165.

4. White M, Oostrom M, Rockhold M. Scalable modeling of carbon tetrachloride migration at the hanford site using the STOMP simulator. Vadose Zone Journal 2008; 7(2):654-666.

5. Sudicky E, Jones J, Park Y, Brookfield A, Colautti D. Simulating complex flow and transport dynamics in an integrated surface-subsurface modeling framework. Geosciences Journal 2008; 12(2):107-122.

6. Diersch HJ, Kolditz O. Variable-density flow and transport in porous media: Approaches and challenges. Advances in Water Resources 2002; 25(812):899-944.

7. Reeves H, Thibodeau P, Underwood R. Incorporation of total stress changes into the ground water model SUTRA. Ground Water 2000; 38(1):89-98.

8. Piggott A, Bobba A, Xiang J. Inverse analysis implementation of the SUTRA groundwater model. Ground Water 1994; 32(5):829-836.

9. Freiboth S, Class H, Helmig R, et al. A model for multiphase flow and transport in porous media including a phenomenological approach to account for deformation-a model concept and its validation within a code intercomparison study. Computational Geosciences 2009; 13(3):281-300.

10. Flemisch B, Darcis M, Erbertseder K, Faigle B, Lauser B, Mosthaf K, Muthing S, Nuske P, Tatomir A, Wolff M, et al.. DuMux: DUNE for multi-phase,component,scale, physics, . . . flow and transport in porous media. Advances in $\mathrm{Wa}$ ter Resources in print; .

11. Mayer K, MacQuarrie K. Solution of the Mo$\mathrm{MaS}$ reactive transport benchmark with MIN3Pmodel formulation and simulation results. Computational Geosciences 2010; 14(3):405-419. 


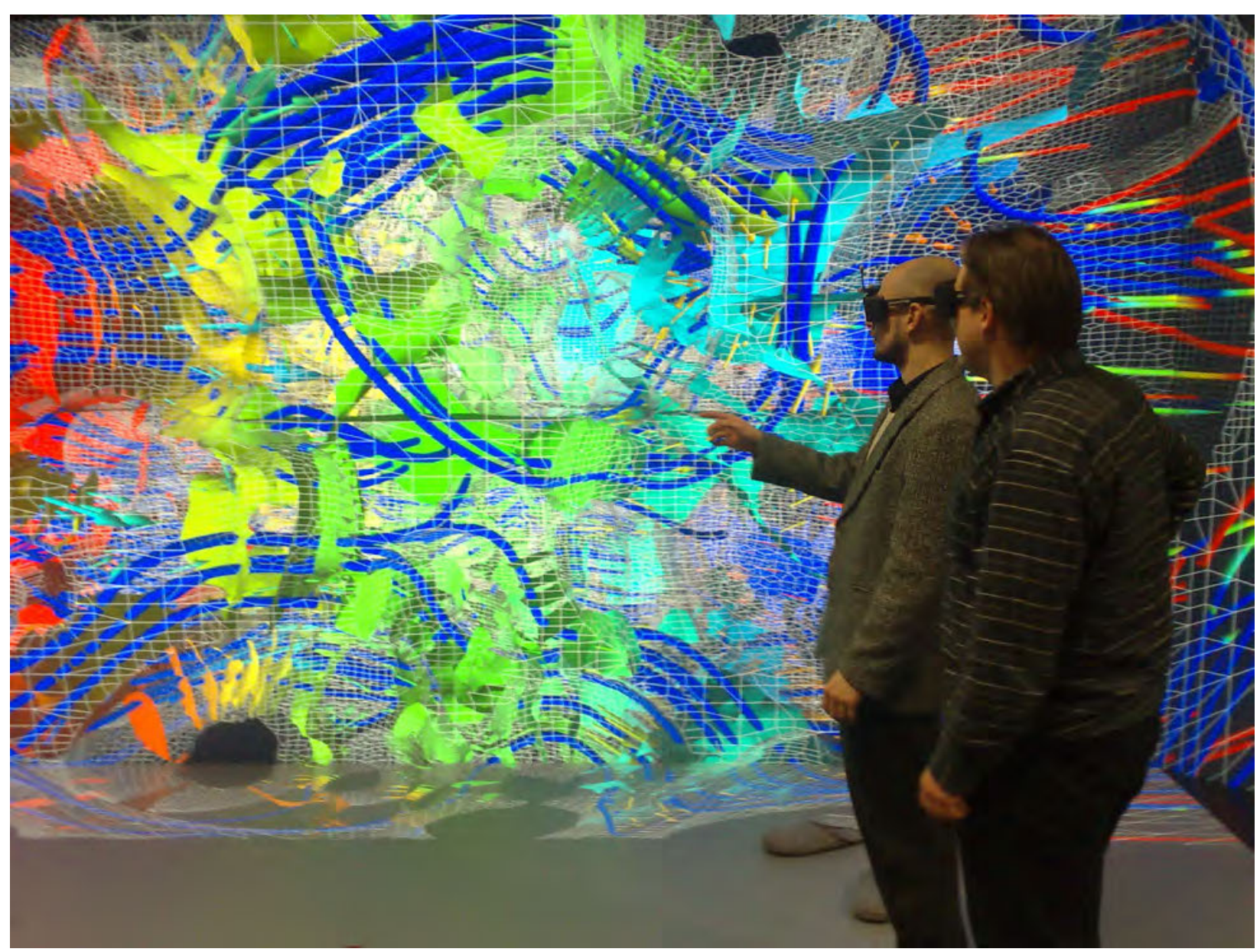

Fig. 12: Visual inspection of a porous medium model in the UFZ VISLab, data: GFZ, photo: Kolditz

12. Prommer H, Barry D, Zheng C. MODFLOW/MT3DMS-based reactive multicomponent transport modeling. Ground Water $2003 ; \mathbf{4 1}(2): 247-257$.

13. Tartakovsky A, Meakin P, Scheibe T. Simulations of reactive transport and precipitation with smoothed particle hydrodynamics. Journal Computational Physics 2007; 222(2):654-672.

14. Diersch H. Finite-element modeling of recirculating density-driven saltwater intrusion processes in groundwater. Advances in Water Resources 1988; 11(1):25-43.

15. Kolditz O. Zur Modellierung und Simulation geothermischer Transportprozesse in untertägigen Zirkulationssystemen. Dissertation, Akademie der Wissenschaften der DDR, Berlin 1990.

16. Kroehn K. Simulation von Transportvorgaengen im klueftigen Gestein mit der Methode der Finiten Elemente. PhD Thesis, Institute of Fluid Mechanics, Hannover University 1991.
17. Wollrath J. Ein Stroemungs- und Transportmodell fuer klueftiges Gestein und Untersuchungen zu homogenen Ersatzsystemen. PhD Thesis, Institute of Fluid Mechanics, Hannover University 1990.

18. Helmig R. Theorie und Numerik der Mehrphasenstroemungen in geklueftet-poroesen Medien. $\mathrm{PhD}$ Thesis, Institute of Fluid Mechanics, Hannover University 1993.

19. Shao H. Simulation von Stroemungs- und Transportvorgaengen im gekluefteten poroesen Medien mit gekoppelten Finite-Elementund und Rand-Element-Methoden. PhD Thesis, Institute of Fluid Mechanics, Hannover University 1994.

20. Lege T. Modellierung des Kluftgesteins als geologische Barriere fuer Deponien. PhD Thesis, Institute of Fluid Mechanics, Hannover University 1995.

21. Kolditz O. Stoff- und Waermetransport im Kluftgestein. Habilitation: Institute of Fluid Mechanics, Hannover University, 1996. 
22. Schulze-Ruhfus M. Adaptive Verfeinerung und Vergroeberung gekoppelter 1D/2D/3D Elemente. Diploma thesis: Institute of Fluid Mechanics, Hannover University, 1996.

23. Barlag C. Adaptive Methoden zur Modellierung von Stofftransport im Kluftgestein. PhD Thesis, Institute of Fluid Mechanics, Hannover University 1997.

24. Thorenz C. Model adaptive simulation of multiphase and density driven flow in fractured and porous media. PhD Thesis, Institute of Fluid Mechanics, Hannover University 2001.

25. Kaiser R. Gitteradaption für die Finite-ElementeModellierung gekoppelter Prozesse in klüftigporösen Medien. PhD Thesis, Institute of Fluid Mechanics, Hannover University 2001.

26. Habbar A. Direkte und inverse Modellierung reaktiver Transportprozesse in klüftig-porösen medien. PhD Thesis, Institute of Fluid Mechanics, Hannover University 2001.

27. Kohlmeier M. Coupling of thermal, hydraulic and mechanical processes for geotechnical simulations of partially saturated porous media. PhD Thesis, Institute of Fluid Mechanics, Hannover University 2006.

28. Rother T. Geometric modelling geo-systems. PhD Thesis, Institute of Fluid Mechanics, Hannover University 2001.

29. Moenickes S. Grid generation for simulation of flow and transport processes in fractured porous media. PhD Thesis, Institute of Fluid Mechanics, Hannover University 2004.

30. Kolditz O, Bauer S. A process-oriented approach to computing multi-field problems in porous media. Journal of Hydroinformatics 2004; 6:225-244.

31. Wang W, Kolditz O. Object-oriented finite element analysis of thermo-hydro-mechanical (thm) problems in porous media. International Journal for Numerical Methods in Engineering 2007; 69(1):162-201.

32. Engelhardt I. Experimental and numerical investigations with respect to the material properties of geotechnical barriers. PhD Thesis, Tuebingen University 2003.

33. de Jonge J. Contributions to computational geotechnics: Non-isothermal flow in lowpermeable porous media. $\mathrm{PhD}$ Thesis, GeoHydrology and HydroInformatics, Center for Applied Geosciences, Tuebingen University 2004.

34. Walsh R. Numerical modeling of THM coupled processes in fractured porous media. $\mathrm{PhD}$ Thesis, GeoHydrology and HydroInformatics, Center for Applied Geosciences, Tuebingen University 2007.
35. Beinhorn M. Contributions to computational hydrology: Non-linear flow processes in subsurface and surface hydrosystems. PhD Thesis, GeoHydrology and HydroInformatics, Center for Applied Geosciences, Tuebingen University 2005.

36. Beyer C. Applied numerical modeling of saturated / unsaturated flow and reactive contaminant transport: evaluation of site investigation strategies and assessment of environmental impact. PhD Thesis, GeoHydrology and HydroInformatics, Center for Applied Geosciences, Tuebingen University 2007.

37. Miles B. Practical approaches to modeling natural attenuation processes at LNAPL contaminated sites. PhD Thesis, GeoHydrology and HydroInformatics, Center for Applied Geosciences, Tuebingen University 2007.

38. Tenzer H. Comparison of the exploration and evaluation techniques of Hot Dry Rock Enhanced Geothermal sites at Soultz-sous-Forêts and Urach Spa in the framework of the geomechanical facies concept. PhD Thesis, GeoHydrology and HydroInformatics, Center for Applied Geosciences, Tuebingen University 2006.

39. Kalbacher T. Geometric modelling and 3-d visualization of hydrogeological systems: Software desing and application. PhD Thesis, GeoHydrology and HydroInformatics, Center for Applied Geosciences, Tuebingen University 2006.

40. Gronewold J. Entwicklung eines InternetInformationssystems zur Modellierung natuerlicher Rueckhalte- und Abbauprozesse im Grundwasser. PhD Thesis, GeoHydrology and HydroInformatics, Center for Applied Geosciences, Tuebingen University 2006.

41. Chen C. Integrating GIS methods for the analysis of geosystems. PhD Thesis, GeoHydrology and HydroInformatics, Center for Applied Geosciences, Tuebingen University 2006.

42. Bauer S. Process based numerical modelling as a tool for aquifer characterization and groundwater quality evaluation. Habilitation: GeoHydrology and HydroInformatics, Center for Applied Geosciences, Tuebingen University, 2006.

43. McDermott C. Reservoir Engineering and System Analysis: Hydraulic, Thermal and Geomechanical Coupled Processes in Geosystems. Habilitation: GeoHydrology and HydroInformatics, Center for Applied Geosciences, Tuebingen University, 2006.

44. Kosakowski G. Transport in fractured media: Concepts, Models, and Applications. Habilitation: GeoHydrology and HydroInformatics, Center for Applied Geosciences, Tuebingen University, 2007. 
45. Park CH, Beyer C, Bauer S, Kolditz O. A study of preferential flow in heterogeneous media using random walk particle tracking. Geosciences Journal 2008; 12(3):285-297.

46. Kolditz O, Delfs JO, Bürger C, Beinhorn M, Park CH. Numerical analysis of coupled hydrosystems based on an object-oriented compartment approach. Journal of Hydroinformatics 2008; 10(3):227-244.

47. Xie M, Bauer S, Kolditz O, Nowak T, Shao H. Numerical simulation of reactive processes in an experiment with partially saturated bentonite. Journal of Contaminant Hydrology 2006; 83(12):122-147.

48. Wang W, Kosakowski G, Kolditz O. A parallel finite element scheme for thermo-hydro-mechanical (thm) coupled problems in porous media. Computers and Geosciences 2009; 35(8):1631-1641.

49. Delfs JO. An Euler-Lagrangian concept for transport processes in coupled hydrosystems. $\mathrm{PhD}$ Thesis, GeoHydrology and HydroInformatics, Center for Applied Geosciences, Tuebingen University in cooperation with Helmholtz Centre for Environmental Research UFZ and Technische Universität Dresden 2010.

50. Shao H. Modelling reactive transport processes in porous media. $\mathrm{PhD}$ Thesis, Technische Universität Dresden, Chair of Applied Environmental System Analysis, Helmholtz Centre for Environmental Research UFZ, Department of Environmental Informatics 2010.

51. Sun F. Computational hydrosystem analysis: Applications to the meijiang and nankou catchments in china. PhD Thesis, Technische Universität Dresden, Chair of Applied Environmental System Analysis, Helmholtz Centre for Environmental Research UFZ, Department of Environmental Informatics 2011.

52. Watanabe N. Finite element method for coupled thermo-hydro-mechanical processes in discretely fractured and non-fractured porous media. PhD Thesis, Technische Universität Dresden, Chair of Applied Environmental System Analysis, Helmholtz Centre for Environmental Research UFZ, Department of Environmental Informatics 2011.

53. Kalbacher T, Schneider C, Wang W, Hildebrandt A, Attinger S, Kolditz O. Parallelized modelling of soil-coupled $3 \mathrm{~d}$ water uptake of multiple root systems with automatic adaptive time step control. Vadose Zone J. 2011; 10:1-9, doi: $10.2136 /$ vzj2010.0099.
54. Rink K, Kalbacher T, Kolditz O. Visual data management for hydrological analysis. Environ. Earth Sci. 2011; in print.

55. Zehner B, Watanabe N, Kolditz O. Visualization of gridded scalar data with uncertainty in geosciences. Computers and Geosciences 2010; 36(10):1268-1275.

56. Kolditz O, Ratke R, Diersch H, Zielke W. Coupled groundwater flow and transport: 1 . verification of variable density flow and transport models. $A d$ vances in Water Resources 1998; 21(1):27-46.

57. Delfs JO, Park CH, Kolditz O. A sensitivity analysis of hortonian flow. Advances in Water Resources 2009; 32(9):1386-1395.

58. Rutqvist J, Barr D, Birkholzer J, Fujisaki K, Kolditz O, Liu QS, Fujita T, Wang W, Zhang CY. A comparative simulation study of coupled thm processes and their effect on fractured rock permeability around nuclear waste repositories. Environmental Geology 2009; 57(6):1347-1360.

59. Wang W, Rutqvist J, Görke UJ, Birkholzer J, Kolditz O. Non-isothermal flow in low permeable porous media: a comparison of Richards' and twophase flow approaches. Environ. Earth Sci. 2011; 62(6):1197-1207.

60. Nowak T, Kunz H, Dixon D, Wang W, Görke UJ, Kolditz O. Coupled 3-D thermo-hydro-mechanical analysis of geotechnical in situ tests. Int. J. Numer. Anal. Meth. Geomech 2011; 48:1-15.

61. Bloecher G, Zimmermann G. Settle3D - A numerical generator for artificial porous media. COMPUTERS \& GEOSCIENCES 2008; 34(12):18271842.

62. Cacace M, Kaiser B, Lewerenz B. Geothermal energy in sedimentary basins: What we can learn from regional numerical models. CHEMIE DER ERDE-GEOCHEMISTRY 2010; 70(3):33-46.

63. Wang W, Kolditz O. Object-oriented finite element analysis of thermo-hydro-mechanical (THM) problems in porous media. International Journal for Numerical Methods in Engineering 2007; 69(1):162-201.

64. Nowak T, Kunz H, Dixon D, Wang W, Görke U, Kolditz O. Coupled 3-d thermo-hydro-mechanical analysis of geotechnological in situ tests. International Journal of Rock Mechanics and Mining Sciences 2011; 48(1):1-15.

65. Görke UJ, Park CH, Wang W, Singh A, Kolditz O. Numerical simulation of multiphase hydromechanical processes induced by $\mathrm{CO}_{2}$ injection in deep saline aquifers. Oil and Gas Science and Technology 2011; 48:1-15. 
66. Teutsch G, Krüger. Water Science Alliance - Priority Research Fields. UFZ, 2010, doi: http://www.watersciencealliance.ufz.de.

67. Wu Y, Wang W, Toll M, Alkhoury W, Sauter M, Kolditz O. Development of a 3D groundwater model based on scarce data: the Wadi Kafrein catchment/Jordan. Environ. Earth Sci. 2011; 64(3):771-785.

68. Sun F, Shao H, Kalbacher T, Wang W, Yang Z, Huang Z, Kolditz O. Groundwater drawdown at Nankou site of Beijing Plain: model development and calibration. Environ. Earth Sci. 2011; 64(5):1323-1333. 